\title{
Role of Doppler Ultrasound and Percutaneous Transluminal Angioplasty in Early Diagnosis and Management of Peripheral Artery Disease
}

\author{
Anggita Kantilaras ${ }^{1 *(1)}$, Agus Widyatmoko ${ }^{2}$ i \\ ${ }^{1}$ Department of Radiology, Faculty of Medicine and Health Sciences, Universitas Muhammadiyah Yogyakarta, Bantul, Indonesia; \\ ${ }^{2}$ Department of Internal Medicine, Faculty of Medicine and Health Sciences, Universitas Muhammadiyah Yogyakarta, Bantul, \\ Indonesia
}

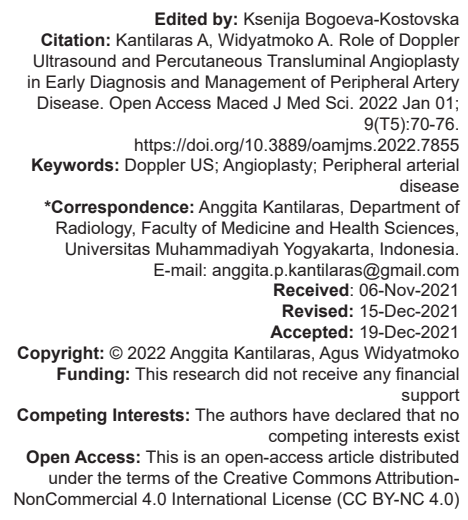

\section{Introduction}

Peripheral arterial disease (PAD) is defined as vascular disorder which peripheral artery's obstruction or constriction is found [1], [2]. Mostly, obstruction of blood supply in PAD is caused by atherosclerosis [1]. Clinical finding of PAD assorted from asymptomatic, weakness in the legs, foot ulcers, gangrene, and critical limb ischemia (CLI) [2], [3]. Early assessment and appropriate therapy of PAD is essential to preserve quality of life, accelerate ulcer healing and diminish the risk of limb amputation [3], [4].

PAD is more found in male and higher in increasing age. PAD's prevalence is $4.3 \%$ in people over 40 years old [4], [5]. Diabetes mellitus (DM) is known as one of major risk factor for PAD [6]. The World Health Organization forecasted an increasing number of DM patient in Indonesia in 30 years, which were 8.4 million into 21.3 million [7]. PAD prevalence in patients with DM ranging from $9.5-13,6 \%$, which is far higher than the general population of $4 \%$ [6].
The presence of DM in PAD can speed up 4 times greater risk of developing CLI [6], [7]. CLI is a clinical syndrome related with PAD which is characterized by chronic ischemic pain particularly in rest or a tissue loss condition, such as wound or gangrene that does not heal over a period of at least 2 weeks [5], [6]. Rutherford classification determines PAD based on clinical presentation and objective test, such as Doppler Ultrasound (DUS), Ankle Brachial Index (ABI) and pulse volume recording [8].

Based on Algorithm of Diagnostic Testing of Suspected CLI by American Heart Association (AHA) Guideline in 2016, if we found nonhealing wound or gangrene with normal $A B I$ result, perfusion assessment is recommended furthermore. Unfortunately, Toe-brachial index (TBI) with waveform, TcPO2 (transcutaneous oxygen pressure) and skin perfusion test are not available in our hospital, so we determine early assessment of PAD with DUS.

The purpose of our case writing is to give information about substantial parameter of DUS in 
determine presence of PAD and define the role of percutaneous transluminal angioplasty (PTA) in PAD. Although DUS is operator dependent, if we can do it properly, possibility early vascular occlusion is never missed. The earlier PAD discovered, faster further treatment conducted, especially PTA. It has been generally used to get over PAD and is suggested as preference management compared open surgery [9], [10], [11], [12], [13].

\section{Case Report}

We report the case of a 65-year-old female patient with intermittent left calf pain for 7 months who came to internal medicine outpatient of PKU Muhammadiyah Gamping Hospital in Yogyakarta. Pain was felt from left groin to the left toe. The pain was felt especially during activity and relieved by rest. She also complained about swollen at left toe. She had amputated of left third and fourth toe 1 year ago caused by gangrene.

Our patient had type 2 DM history since 10 years ago. Glibenclamide and metformin was given to our patient. Unfortunately, she discontinued the oral medication. Besides that, she had hyperlipidemia for 10 year ago, but she had not consumed medicine regularly. She is also had hypertension and got ACE inhibitor medication. 1 year ago, left third toe and fourth toe were turn to black and had ulcer or gangrene, so amputation was done by surgeon specialist. No family member that has similar symptom history, but the patient's father had diabetes history.

Vital sign examination revealed a general state of weakness with Glasgow Coma Score (GCS) 456. Blood pressure were 150/100 mmHg. Pulse, respiratory rate and axillary temperature were normal. Pain scale examination showed score 5 based on Visual Analog Scale, it means moderate pain. The patient's body weight was $77 \mathrm{~kg}$; body height was $153 \mathrm{~cm}$, with body mass index showed $33 \mathrm{~kg} / \mathrm{m}^{2}$

Examination of head and neck showed no anemic in conjunctiva, no icteric in sclera, no dyspnea and no cyanosis. There was no increase of jugular venous pressure or any enlargement of the neck lymph nodes. The chest and cardiac examination revealed normal result. Normal bowel sound, tympanic percussion and normal palpation were found in our patient. Spleen and liver were not palpable.

Extremity examination confirmed swollen in the left foot and ischemic ulceration (Figure 1). Left foot turn to black. She denied any previous trauma and fever. Resting $A B \mid$ result showed 1.14 at right toe, 1.12 at left toe, both of these means normal. Whereas TBI value showed 0.9 at right toe, 0.5 at left toe, it means abnormal at left toe and normal at right toe. Arterial

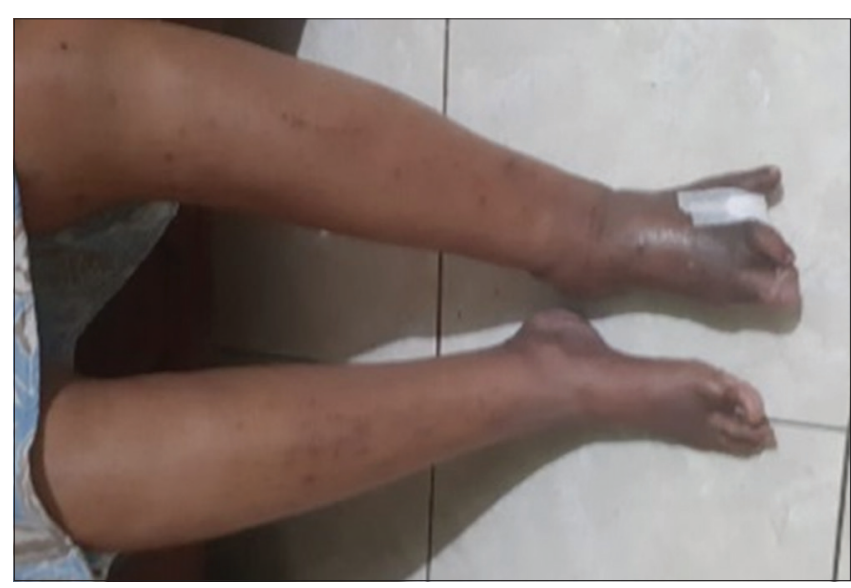

Figure 1: Swollen and rubor in the middle of left calf until to toe Our patient is planned for hospitalization. Then, DUS examination was done as mentioned below

pulsation was normal in femoral, popliteal and posterior tibial artery, but pulsation of anterior tibial artery was diminished. Peripheral oxygen saturation examination in the left foot digiti I, II and V were $83 \%, 84 \%$ and $85 \%$ respectively, while in the left foot digit III and IV cannot be examined caused by amputated history previously. Based on history finding and physical examination, our patient was diagnosed to have Rutherford-Baker classification stage 2 .

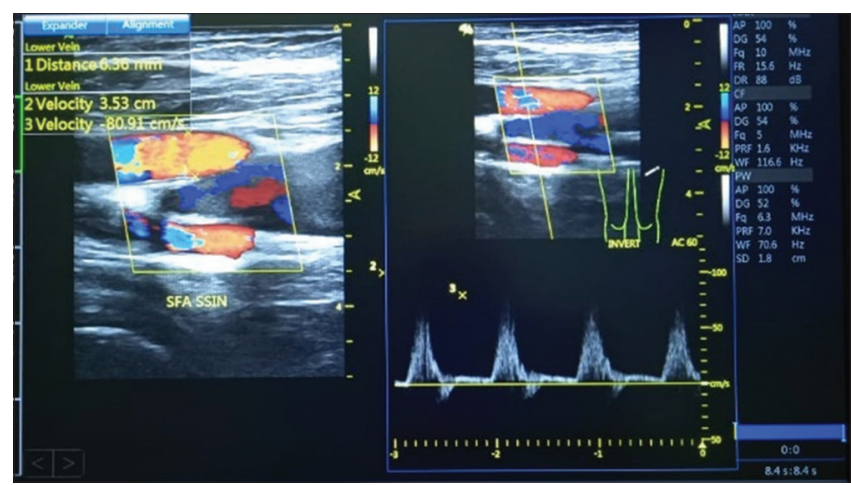

Figure 2: No clear spectral window in superficial femoral artery

DUS of femoral superficial artery showed there were spectral narrow and reversal flow finding, but no clear spectral window in it (Figure 2). Clear spectral window, spectral narrow and reversal flow were revealed in DUS of poplitea artery (Figure 3). Whereas DUS of anterior tibial artery showed no clear spectral window, no clear spectral narrow and no reversal flow

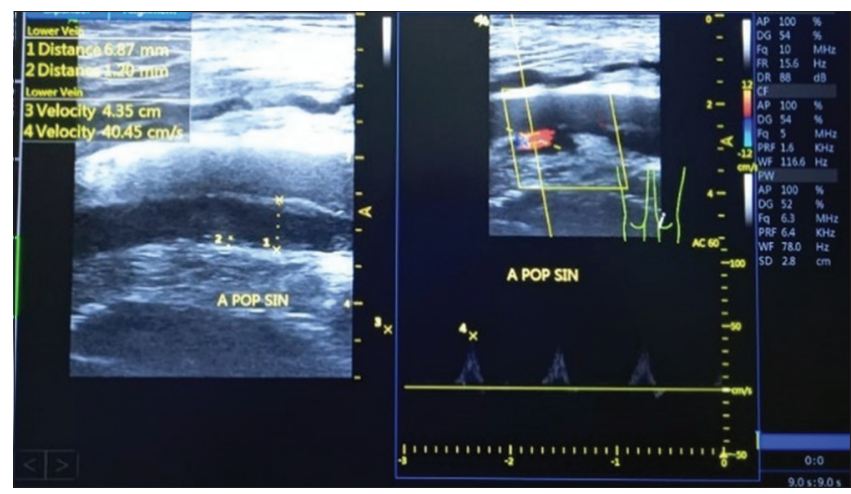

Figure 3: There were many plaque in poplitea artery. No stenosis in it 


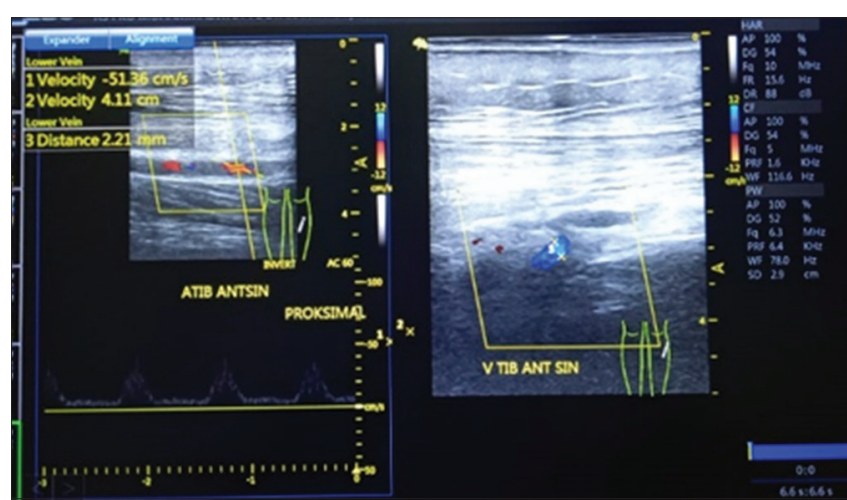

Figure 4: There were many plaque in anterior tibia artery. No clear spectral window, no spectral narrow and no reversal flow

(Figure 4). Furthermore, clear spectral window and reversal flow were appeared in DUS of posterior tibial artery, but no spectral narrow in it (Figure 5).

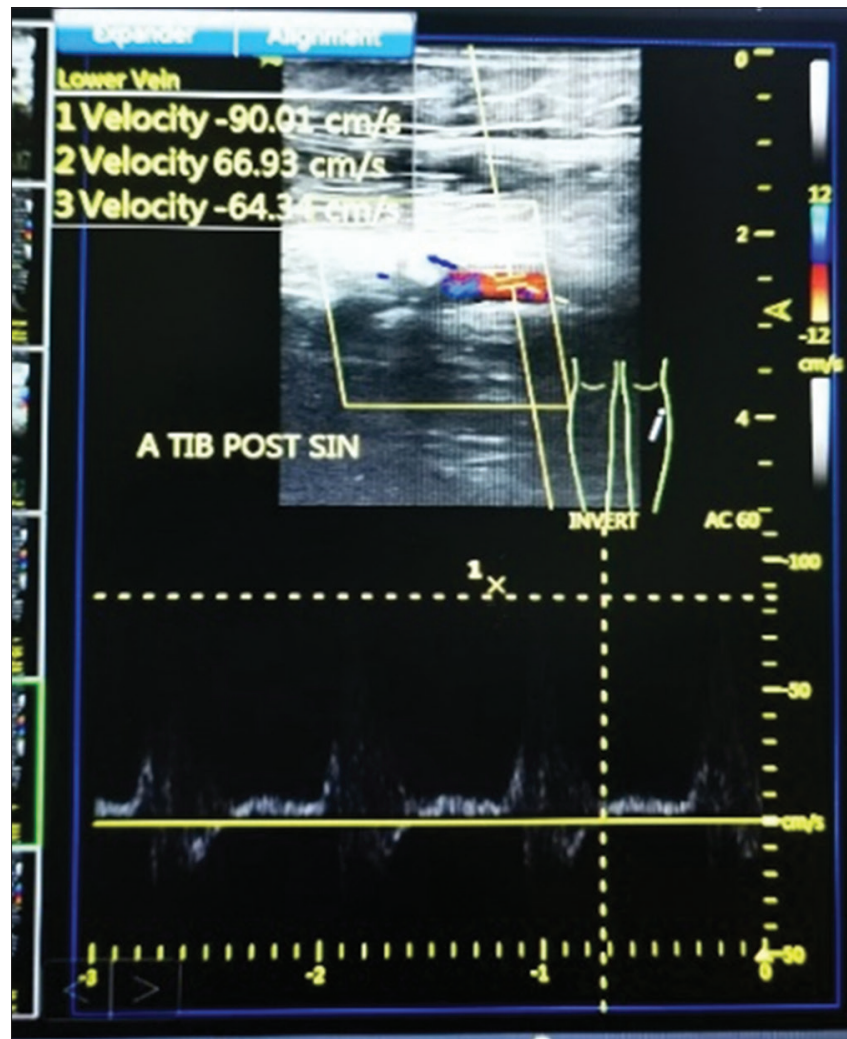

Figure 5: Clear spectral window and reversal flow in posterior tibial artery

Our patient was also planned for arteriography followed by PTA. We asked suggestion from cardiologist about our case. Antiplatelet infusion was given 3 days before PTA. 1 day before PTA, it was stopped and planned for PTA. After got informed consent from our patient, arteriography and PTA was done at catheterization laboratory (cath lab) at PKU Muhammadiyah Gamping Hospital (Figure 6). Our team were Interventional Radiology team which do invasive minimal procedure to diagnose the presence of vascular occlusion, stenosis or other causes that can causes pain in the leg. Arteriography finding in our patient was partial stenosis of proximal of anterior tibia

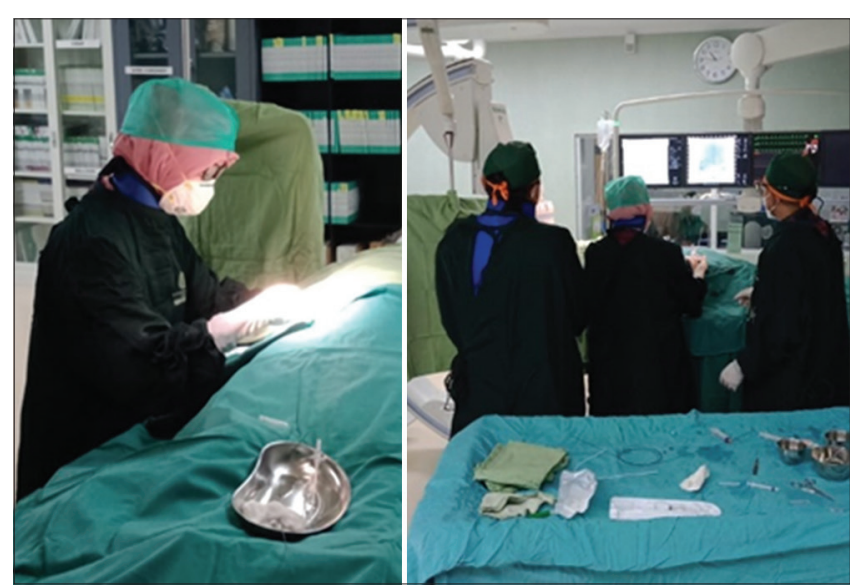

Figure 6: Percutaneus Transluminal Angioplasty was done at cath lab at PKU Muhammadiyah Gamping Hospital

artery and middle of anterior tibia artery (Figure $7 \mathrm{~b}-\mathrm{c}$ ). Therefore, the patient carried out PTA therapy to restore distal perfusion.

PTA was done by local anesthesia, which injected in right groin. A guide wire and catheter inserted to femoral artery through introducer sheath. A deflated balloon catheter inserted and pushed forward along the microwire to the site of obstruction at middle of anterior tibia artery (Figure 7e). Our interventional radiology team used angioplasty balloon with $3 \mathrm{~mm}$ in wide and $80 \mathrm{~mm}$ in length. Then, inflate the balloon to opens up the stenosis or occlusion. After PTA, no stenosis in middle of anterior tibial artery (Figure 7f). PTA wasn't done in proximal of anterior tibia artery because its curved location. Stenosis in proximal of anterior tibia artery was adjacent to the branching of the popliteal artery become tibioperoneal trunk and anterior tibial artery (Figure $7 \mathrm{~b}$ )

After PTA, general condition of our patient was good. GCS revealed 4-5-6 and vital sign result was normal. 2 days later, peripheral oxygen examination in left digit I, II and $\mathrm{V}$ were $98 \%, 98 \%$ and $98 \%$, respectively. Besides that, swollen foot was also diminished. The patient was discharged and advised to control routinely to surgeon, internal medicine and interventional radiology clinics.

\section{Discussion}

PAD is defined as vascular disorder which peripheral artery's obstruction or constriction is found. Chronic limb ischemia (CLI) also referred to as CLI (one of the PAD key terms) is clinical finding which there are chronic claudication, foot ulcer and wound that do not heal for a period at least two weeks, which is proven as occlusive artery disease [5], [6], [3]. Initially, atherosclerosis is happened, and then there is decrease blood flow to distal extremities [6]. Proper diagnosis and 


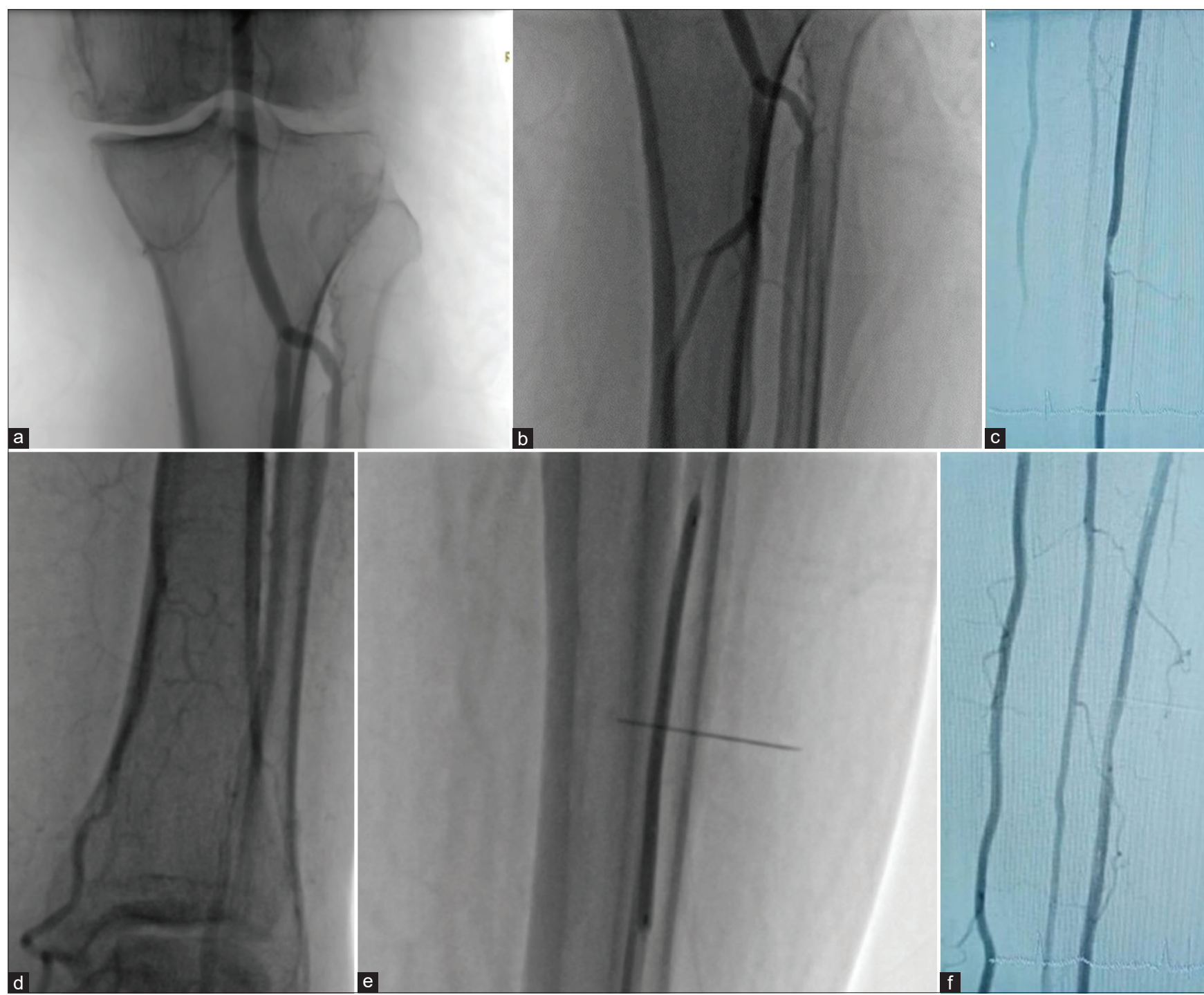

Figure 7: (a). No stenosis in poplitea artery, (b). Partial stenosis in proximal of anterior tibia artery, (c). Partial stenosis in middle of anterior tibia artery (in mid calf in left leg) (d). No stenosis in posterior tibia artery. (e). Inflated balloon in site of stenosis in anterior tibia artery (f). After Percutaneus Transluminal Angioplasty: No stenosis, good flow

appropriate treatment and multidisciplinary approach can improve the prognosis and prevent limb loss or amputation, which impact to quality of life [1], [2], [7].

The most severe spectrum of PAD was known by progressive claudication which can develop to nocturnal rest pain [6]. The severity of CLI may be classified into without symptom, claudication, CLI followed by rest pain and CLI followed by tissue damage [5], [9], [13]. It is started with the reduction blood flow to the lower extremities especially for activity, so initial symptom which appears was pain that more severe with activity and less severe with rest. Then, the diameter artery will decrease gradually, therefore blood flow to lower extremity will diminish significantly, particularly when take a rest. So it is often called nocturnal rest pain. Besides that, the pain often more severe at night when the patient is lying down.

Sometimes, diagnosis of PAD can be difficult, especially if $A B I$ value is normal. The sensitivity of $A B I$ is ranging from 68 to $84 \%$ and specificities from 84 to
99\% [11]. Based on recent medical history, medical history previously and physical examination in our case, diagnosis of $P A D$ is possible, although $A B I$ value is normal. $A B I$ value in this case showed 1.14 at right toe and 1.12 at left toe. $A B I$ in the both of toe were normal.

People with DM has characteristic extremity artery is showed normal $A B I$ value or more than 1,4 . Normal $A B I$ value or more than 1,4 reveal that the arteries cannot be compressed. It is often found in people with DM or chronic kidney disease [14], [15]. It is concordance with Park et al. that declare that normal or elevated $A B I$ can be caused by sclerosis of the medial wall of lower extremity artery [14]. Therefore, we can conclude that a normal $A B I$ value is cannot exclude PAD in our patients.

If previous predication and lower extremity investigation propound of PAD with ordinary assessment of $A B I$, is suggested to check extremity perfusion, as referred below in Figure 8 [11]. $A B I$ is not recommended in patients with vascular hardness and cannot find the 


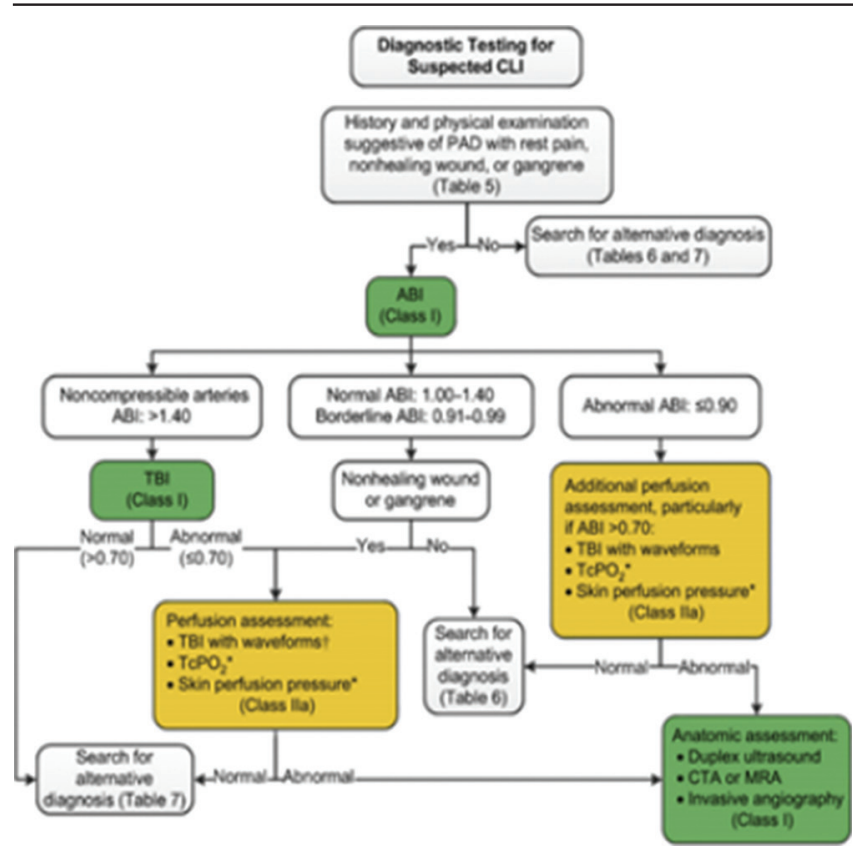

Figure 8: Diagnostic testing for suspected chronic limb ischemia [5]

early finding of sclerosis artery [14]. In our case, ABI value is normal. TBI is more offered in our case because toe vessels are less susceptible to vascular stiffness [15]. TBI is usually limited to patients who have normal or elevated $A B I$ value or have vessel stiffness caused by relevant comorbidities, especially DM in our case [14], [15].

There are many factors can affect prognosis of PAD patients with diabetes, for example the presence of infection, comorbidity, neuropathy and immunological history of the patient. DM can expedite atherosclerosis process and had a 5-10 times higher amputation risk than people that no had diabetes history [6], [16]. It is caused by its tendency in the distal arteries, so it has correlation with neuropathy finding and higher risk of infection [16].

TBI value in our patient showed 0.5 in left toe. If we concern with Algorithm of Diagnostic Testing for Suspected CLI in Figure 8 above, abnormal TBI will be followed by TBI with wave forms, $\mathrm{TcPO}_{2}$ and skin perfusion pressure. Unfortunately, all of examination above is not yet available in our hospital. To overcome our limitation of perfusion assessment, we must concern with DUS finding. It can be the sole imaging modality used to guide endovascular procedures, which is give information about level stenosis and physiological severity of a stenosis [17]. According to Hwang (2017), the sensitivity and specificity of DUS in determine narrowing of vascular diameter as less than or greater than $50 \%$ are $77-82 \%$ and $92-98 \%$, respectively [4], [18].

Normal finding of DUS in lower extremity arteries is defined as an upper pulsatory spectral wave which has triphasic flow pattern [18]. Normal heartbeat flow be composed by a tall, narrow and sharp systolic peak in first phase, then by early diastolic reversal flow in second phase and followed by late diastolic forward in third phase [18], [19]. Normal characteristic of artery in extremities is high peripheral resistance, so this is will result diastolic reversal flow.

There are many parameters which is we must concern about DUS finding: (1) clear spectral window, (2) spectral narrow/no spectral broadening, and (3) presence of reversal flow [20] (Table 1).

Table 1: Comparison between DUS finding and angiogram finding in our case

\begin{tabular}{lllll}
\hline DUS finding & $\begin{array}{l}\text { Clear spectral } \\
\text { window }\end{array}$ & $\begin{array}{l}\text { Spectral } \\
\text { narrow }\end{array}$ & $\begin{array}{l}\text { Reversal } \\
\text { flow }\end{array}$ & $\begin{array}{l}\text { Angiogram } \\
\text { finding }\end{array}$ \\
\hline Femoral superficial artery & - & + & + & No stenosis \\
Poplitea artery & + & + & + & No stenosis \\
Anterior tibial artery & - & - & - & Partial stenosis \\
Posterior tibial artery & + & - & + & No stenosis \\
\hline DUS: Doppler ultrasound & & & &
\end{tabular}

Spectral waveform in superficial femoral, poplitea and posterior tibial artery in our case appear as triphasic pattern. However, monophasic pattern was found in anterior tibial artery. It is concordance with examination by Sibley et al. (2017), which declare that loss of vascular resistance in PAD results in the loss of reversal flow, so conduce monophasic pattern [5], [18]. Besides that, we can found no clear spectral window in anterior tibial artery. It means blood cells are moving at different speed or there is turbulence flow within anterior tibial artery in our case.

Based on Table 1, clear spectral window was not too taken effect with angiogram finding. Although there is no clear spectral window in superficial femoral artery, there is reversal flow in it, so it means no stenosis and corresponding with our angiogram result.

Similar with clear spectral window, although there is spectral broadening in anterior tibia and posterior tibia artery, but no reversal flow in anterior tibia artery (partial stenosis in our angiograph) dan there is reversal flow in posterior tibia artery (no stenosis in our angiogram). If we concerned that spectral broadening in posterior tibia artery is not as wide as in anterior tibia artery. According to Hwang (2017), spectral broadening is prominent, with a diameter reduction of $20-50 \%$ [18]. Therefore, based on three parameters and our angiogram finding as mentioned above, reversal flow is most important parameter to establish presence of stenosis.

According to Lower Extremity PAD Guideline, if leg symptoms are not found in patient, arteriography is not recommended for determination of presence of limb vascular abnormality, because depiction of anatomy will not establish kind of treatment [5]. In our case, our patient complained about intermittent left calf pain for 7 years, so arteriography was recommended to restore distal perfusion. Besides that, it was corresponding with Thukkani's statement that represent revascularization is typically considered in patients with PAD who had any 1 of 3 diverse clinical finding: (1) ischemic rest pain which get poor response to medical therapy (2) CLI or (3) acute limb 
ischemia [11]. The urgency and goals of treatment depend on the clinical syndrome, comorbidities and occlusive anatomic level [7].

Digital subtraction angiography is recommended as the gold standard examination which represent detailed vascular mapping until distal end. Contrast agent is injected through catheter and the flow of contrast filling vasculature will be obtained [5]. PTA is endovascular revascularization, which can be performed in the same circumstances. It is a minimally invasive therapy for the treatment of patients with PAD who suffer from intermittent claudication or CLI. Before PTA, diagnostic arteriography must be done [5]. Arteriography finding was partial stenosis in middle of anterior tibia artery, $4 \mathrm{~cm}$ in length of stenosis and $40 \%$ in vascular patency. There is no finding of collateral vessels as compensation to stenosis in its upper artery. It was consistent with research of Thulasikumar (2017), which represent the vascular collateral formation in diabetes patient was impaired, so vascular flow to distal tissue became inadequate and then severe ischemia was more happened [4].

In our case, after PTA there was no stenosis again in middle anterior tibia artery. Initial success rates are in the $90 \%$ range for PTA of the superficial femoral artery and below of popliteal arteries. However, for a long period of time (5 years), success rate of PTA varied from 53 to $70 \%$, depending on the severity of disease and which diseased blood vessel was treated [21]. According to Robertson et al. (2017), the success rate of PTA depends on severity of PAD (intermittent claudication or occlusion), the length of lesion, quality of vessel, concomitant disease and risk factors [8]. Our patient is categorized in chronic limb ischemia, type of PAD was stenosis, no thrombus, $4 \mathrm{~cm}$ in the length of lesion, had diabetes in for long times (10 years), vessels tend had stiffness caused by diabetes history. Besides that, our patient had hyperlipidemia and hypertension as risk factor that can affect success rate of PTA. Therefore, further follow-up is needed.

The correlation between dyslipidemia and PAD is in the occurrence of atherosclerosis. Patients with dyslipidemia provide a risk factor for the onset of atherosclerosis. Dyslipidemia manifests with hyperglycemia, excess free fatty acids and insulin resistance which causes increment of oxidative stress, endhotelin-1, angiotensin II and platelet activation, deflation of nitric oxide and alleviation of fibrinolysis which all cause endothelium dysfunction [2].

\section{Conclusion}

Reversal flow finding in DUS is most important parameter to establish the presence of stenosis. PTA is adequate to give revascularization stenosis in PAD.
More earlier PAD's diagnosis, more earlier PTA is done, so it can prevent limb amputation.

\section{References}

1. Azkiyah FF, Djajakusumah TM, Ekowati RR. Peripheral arterial disease among diabetic patients in Dr. Hasan Sadikin general Hospital Bandung 2012. Althea Med J. 2015;2(2):557. https:// doi.org/10.15850/amj.v2n2.557

2. Sarjana D, Isnanta R, Thamrin A. Correlation between cardiovascular risk factors with peripheral arterial disease in kidney failure patients undergoing hemodialysis for more than three months in haji adam malik general hospital medan year 2018. Int J Res Sci Manag. 2019;6(7):58-64. https://doi. org/10.5281/zenodo.3354249

3. Tummala S, Scherbel D. Clinical assessment of periphera arterial disease in the office: What do the guidelines say? Semin Intervent Radiol. 2018;35(5):365-77.

4. Thulasikumar G, Vijayasarathy S. Assessment of prevalence and risk factors of peripheral arterial disease in diabetic. International J of Surgery and Medicine. 2017;3:156-66.

5. Gerhard-Herman MD, Gornik HL, Barrett C, Barshes NR, Corriere MA, Drachman DE, et al. 2016 AHA/ACC guideline on the management of patients with lower extremity peripheral artery disease: A report of the American College of Cardiology/ American Heart association task force on clinical practice guidelines. J Am Coll Cardiol. 2017;69(11):e71-126. https://doi. org/10.1016/j.jacc.2016.11.007

PMid:27851992

6. Givani CL, Novida H. Critical limb ischemia in a diabetes mellitus patient with atrial fibrilation. Curr Intern Med Res Pract Surabaya J. 2020;1(2):25.

7. Thiruvoipati T. Peripheral artery disease in patients with diabetes: Epidemiology, mechanisms, and outcomes. World J Diabetes. 2015;6(7):961-9. https://doi.org/10.4239/wjd.v6.i7.961 PMid:26185603

8. Hardman RL, Jazaeri O, Yi J, Smith M, Gupta R. Overview of classification systems in peripheral artery disease. Semin Intervent Radiol. 2014;31(4):378-88. https://doi. org/10.1055/s-0034-1393976

PMid:25435665

9. Hochlenert D, Engels G, Morbach S, Schliwa S, Game FL. Diabetic Foot Syndrome From Entity to Therapy. Vol. 1. Berlin: Springer; 2018. p. 1-18.

10. Depth I. Percutaneous therapies for peripheral artery disease Circulation. 2016;134(24):2008-27. https://doi.org/10.1161/ CIRCULATIONAHA.116.022546 PMid:27956404

11. Thukkani AK, Kinlay S. Endovascular intervention for periphera artery disease. Circ Res. 2015;116(9):1599-613. https://doi. org/10.1161/CIRCRESAHA.116.303503 PMid:25908731

12. Robertson L, Paraskevas KI, Stewart M. Angioplasty and stenting for peripheral arterial disease of the lower limbs: An overview of cochrane reviews. Cochrane Database Syst Rev. 2017;2:CD012542. https://doi.org/10.1002/14651858. CD012542

13. Kinlay S. Management of critical limb ischemia. Circ Cardiovasc Interv. 2016;9(2):e001946. https://doi.org/10.1161/ CIRCINTERVENTIONS.115.001946

PMid:26858079 
14. Park SC, Choi CY, Ha YI, Yang HE. Utility of toe-brachial index for diagnosis of peripheral artery disease. Arch Plast Surg. 2012;39(3):227-31. https://doi.org/10.5999/aps.2012.39.3.227 PMid:22783531

15. Hoyer C, Sandermann J, Petersen LJ. The toe-brachial index in the diagnosis of peripheral arterial disease. J Vasc Surg. 2013;58(1):231-8. http://dx.doi.org/10.1016/j.jvs.2013.03.044 PMid:23688630

16. Spreen MI, Gremmels H, Teraa M, Sprengers RW, Verhaar MC, Van Eps RG, et al. Diabetes is associated with decreased limb survival in patients with critical limb ischemia: Pooled data from two randomized controlled trials. Diabetes Care. 2016;39(11):2058-64. http://dx.doi.org/10.2337/dc16-0850 PMid:27612499

17. Pieruzzi L, Napoli V, Goretti C, Adami D, lacopi E, Cicorelli A, et al. Ultrasound in the modern management of the diabetic foot syndrome: A multipurpose versatile toolkit. Int J Low Extrem Wounds. 2020;19(4):315-33.
18. Hwang JY. Doppler ultrasonography of the lower extremity arteries: Anatomy and scanning guidelines. Ultrasonography. 2017;36(2):111-9. http://dx.doi.org/10.14366/usg.16054 PMid:28219004

19. Sibley RC, Reis SP, MacFarlane JJ, Reddick MA, Kalva SP, Sutphin PD. Noninvasive physiologic vascular studies: A guide to diagnosing peripheral arterial disease. Radiographics. 2017;37(1):346-57. http://dx.doi.org/10.1148/rg.2017160044 PMid:27689831

20. Revzin M, Imanzadeh A, Menias C, Pourjabbar S. Optimizing image quality when evaluating blood flow at Doppler US: A tutorial. Radiographics. 2019;39(5):1501-23. http://dx.doi. org/10.1148/rg.2019180055 PMid:31398088

21. De Sanctis JT. Percutaneous interventions for lower extremity peripheral vascular disease. Am Fam Physician. 2001;64(12):1965-72.

PMid:11775762

Author Queries???

AQ1: Kindly provide high resolution image 